\title{
Does variation in photosynthetic rate explain variation in growth rate and yield?*
}

\section{H. Lambers}

Department of Plant Ecology, University of Utrecht, Lange Nieuwstraat 106, 3512 PN Utrecht, Netherlands

Received 7 July 1987; accepted 17 July 1987

Key words: photosynthetic rate, growth rate, yield

\begin{abstract}
This paper discusses the basis of variation in growth rate and production between species and between genotypes of one species. Examples are given showing that such variation is due to a different pattern of investment of photosynthates. Other examples show that such variation is due to the net assimilation rate, of which photosynthesis is a major component. Subsequently, a number of biochemical, morphological and anatomical aspects causing variation in photosynthesis are discussed. In this context patterns of distributing nitrogen over the various leaves in the canopy are also discussed. It is concluded that there is scope for improving canopy photosynthesis and that this may indeed lead to greater productivity. However, the way in which photosynthesis has to be modified is by subtle changes in anatomical and morphological features and in the pattern of investment of nitrogen, rather than in the basic biochemistry of photosynthesis itself. Such modification may lead to conditions for the leaf which are closer to those for optimum performance of photosynthesis, including improved water-use efficiency and ratio of carbon gain to invested nitrogen.
\end{abstract}

\section{Introduction}

Species from contrasting habitats may differ vastly in their maximum relative growth rate under optimum conditions; species from productive environments tend to have an inherently higher growth rate than those from nutrient-poor, dry or otherwise unfavourable milieus (Grime \& Hunt, 1975). Genotypic variation for growth rate has also been found among genotypes of one species, e.g. Lolium perenne (Wilson, 1975, 1982) and Plantago major (Dijkstra \& Lambers, 1986). A vast

\footnotetext{
* Paper presented at the symposium 'The Global Carbon Cycle', held 24 October 1986 on the occasion of the retirement of Prof Dr Ir J. F. G. M. Wintermans from the University of Nijmegen.
} 


\section{H. LAMBERS}

amount of literature is available about genotypes of crop species differing in yield. Surely, photosynthesis is an absolute requirement for growth and crop yield, but does this imply that variation in growth rate and yield is also due to variation in photosynthesis?

This paper first aims to review a number of case studies describing variation in growth rate and yield, and to analyse the question in how far photosynthesis plays a role in determining the observed variation. A second aim is to further analyse the background of variation in photosynthesis, particularly when it does explain variation in growth or yield.

\section{Growth analysis}

A functional growth analysis, based on experiments in which plants are grown under standard conditions and harvested at regular intervals, can provide the first clues towards an understanding of variation in growth rate between genotypes or species. The relative growth rate (RGR; $\mathrm{mg} \mathrm{g}^{-1}$ (total plant) $\mathrm{d}^{-1}$ ) can be calculated (e.g. Hunt, 1982; Lambers \& Dijkstra, 1987; see Table 1 for a brief description of abbreviations used in growth analyses):

$$
\operatorname{RGR}=(1 / W) \mathrm{d} W / \mathrm{d} t
$$

where $W$ is the total dry or fresh weight (g) of the investigated plants, and $\mathrm{d} W$ is the dry or fresh weight increment $(\mathrm{mg})$, during the interval $\mathrm{d} t$ (days).

Differences in RGR may be due to a 'physiological' component, the net assimilation rate (NAR; $\mathrm{g} \mathrm{m}^{-2}$ (leaf area) $\mathrm{d}^{-1}$ ), which is largely the balance of the rate of photosynthesis and that of respiration in the entire plant:

$$
\text { NAR }=(1 / L A) d W / d t
$$

where LA is the leaf area of the investigated plants $\left(\mathrm{m}^{2}\right)$.

Differences in RGR may also be due to a 'morphological' component, the leaf area ratio (LAR; $\mathrm{m}^{2}$ (leaf area) $\mathrm{kg}^{-1}$ (total plant)).

$$
\mathrm{LAR}=\mathrm{LA} / W
$$

RGR is the product of NAR and LAR:

$$
\mathrm{RGR}=\mathrm{NAR} \times \mathrm{LAR}
$$

The leaf area ratio can be further analysed. Variation may be due to a difference in 'investment' in leaf biomass, i.e. a difference in leaf weight ratio (LWR; g (leaf weight) $\mathrm{g}^{-1}$ (total plant weight), or to a difference in specific leaf area (SLA; $\mathrm{m}^{2}$ (leaf area) $\mathrm{kg}^{-1}$ (leaf weight)):

$$
\mathrm{LAR}=\mathrm{LWR} \times \mathrm{SLA}
$$


Table 1. Explanation of abbreviations used in growth analyses and the preferred SI units in which they are expressed, listed in alphabetical order. Numbers in the last column refer to the equation in which the abbreviations first appear in the text. Weight is expressed as either dry or fresh weight.

\begin{tabular}{llll}
\hline Abbreviation & Meaning & Preferred SI units & Equation \\
AGR & Absolute growth rate & $\mathrm{mg} \mathrm{d}$ & \\
CGR & Crop growth rate & $\mathrm{mg} \mathrm{m}^{-1} \mathrm{~d}^{-1}$ & 6 \\
LAI & Leaf area index & $\mathrm{m}^{2} \mathrm{~m}^{-2}$ & 6 \\
LAR & Leaf area ratio & $\mathrm{m}^{2} \mathrm{~kg}^{-1}$ & 3 \\
LWR & Leaf weight ratio & $\mathrm{g} \mathrm{g}^{-1}$ & 5 \\
NAR & Net assimilation rate & $\mathrm{g} \mathrm{m}^{-2} \mathrm{~d}^{-1}$ & 2 \\
RGR & Relative growth rate & $\mathrm{mg} \mathrm{g}^{-1} \mathrm{~d}^{-1}$ & 1 \\
SLA & Specific leaf area & $\mathrm{m}^{2} \mathrm{~kg}^{-1}$ & 5 \\
\hline
\end{tabular}

Whenever the experimental plants are no longer growing exponentially, e.g. when the canopy has closed, it may be more appropriate to analyse the crop growth rate (CGR; in $\mathrm{mg} \mathrm{m}^{-2}$ (ground area) $\mathrm{d}^{-1}$ ) or absolute growth rate (AGR; $\mathrm{mg} \mathrm{d}^{-1}$ ) (Warren Wilson, 1981). CGR is the product of NAR and the leaf area index (LAI; $\mathrm{m}^{2}$ (leaf area) $\mathrm{m}^{-2}$ (ground surface area):

$$
\mathrm{CGR}=\mathrm{NAR} \times \mathrm{LAI}
$$

CGR and RGR are related via the dry weight of plants per unit area of ground (stand biomass):

$$
\text { CGR }=\text { Biomass } \times \text { RGR }
$$

A functional growth analysis is the first step in any analysis of morphological, physiological or biochemical factors determining RGR. However, surprisingly few such comparisons have been made between species or genotypes.

\section{Some analyses of inherent differences in relative growth rate}

Pons (1977) compared the growth of the shade-avoiding Cirsium palustre and the shade-tolerant Geum urbanum. At a high-quantum flux density the growth rate of the shade-avoiding species was significantly greater than that of the shade-tolerant species. The difference in RGR was apparently caused by a difference in NAR, which was reflected in a greater photosynthetic capacity. The $50 \%$ greater LWR in Cirsium was more than compensated for by a reduction in SLA, so that the LAR was slightly lower than in Geum.

A comparison of another shade-avoiding species (Galinsoga parviflora) with two shade-tolerant species (Stachys sylvatica and Urtica dioica) provides another example showing that a high NAR is correlated with a high RGR; however in this example a higher LAR also contributed to the higher RGR of G. parviflora (Corré, 
1983). A combination of both a higher NAR and a higher LAR contributing to a higher RGR was also found in a comparison of the growth of Helianthus annuus with that of two tree species (Betula verrucosa and Populus tremula; Jarvis \& Jarvis, 1964).

Higgs \& James (1969) compared two fast growing grass species (Lolium perenne and Agrostis tenuis) with two slow growing ones (Nardus stricta and Sieglingia decumbens). The differences in RGR were brought about mainly by the LAR, rather than the NAR. The NAR was lowest in Sieglingia, but fairly similar in the other three species. An analysis of the growth of two subspecies of Plantago major has also led to the conclusion that the 'morphological' component offers an explanation for variation in RGR. Subspecies pleiosperma has an inherently higher RGR than subspecies major (Kuiper, 1983; Dijkstra \& Lambers, 1986), but it had a lower NAR. This lower NAR was more than compensated by a higher LAR, largely due to a higher SLA and to a minor extent a higher LWR. Thus, the high growth rate of subspecies pleiosperma is associated with a large investment in photosynthetically active area (a high LAR) rather than with the carbon exchange rate (Lambers \& Dijkstra, 1987).

The conclusion from these examples is that only in some comparisons of sun with shade plants the difference in relative growth rate is (partly) due to the physiological component, i.e. the net assimilation rate (Pons, 1977; Corré, 1983). In other comparisons the morphological component (the specific leaf area or the leaf weight ratio) offers an explanation for differences in relative growth rate (Higgs \& James, 1969; Dijkstra \& Lambers, 1986).

Since both respiration and photosynthesis are components of the net assimilation rate, a further analysis warrants an investigation of these two processes. Losses of carbon, for example volatiles from the leaves and exudates from the roots, may also affect the net assimilation rate, but very little quantitative information is available about this subject (Lambers \& Dijkstra, 1987).

\section{Some analyses of inherent differences in crop yield}

Gifford et al. (1984) reviewed the literature on the genetic components determining greater yield in modern cultivars of a number of crop species compared to the ones introduced a number of decades ago. They concluded that the increased harvest index, i.e. the ratio of the weight of the harvestable product, such as the grain in cereals and the nuts in peanuts, and the total (above-ground) weight, explains the higher yields of modern cultivars. Photosynthesis per unit leaf area of modern cultivars is not higher than that of older ones or the original ancestors. This is perhaps not so surprising in view of the results of comparisons of sun and shade species cited above. Presumably, the selection for higher yield coincided with that for characteristics of shade plants. Indeed, the quantum flux density most leaves of modern wheat varieties are exposed to is likely to be lower than that of their ancestors. Further increments in crop photosynthesis, rather than leaf photosynthesis, might be obtained by increasing the photosynthesis of leaves at the top of the canopy, at the expense of those situated lower in the canopy. 
Apel et al. (1973) found a close correlation between flag leaf area and grain yield in a comparison of 100 cultivars of Triticum aestivum. In cultivars with the greatest distance from the regression line, flag leaf photosynthesis showed extreme values; high-yielding genotypes with small flag leaves had very high rates of photosynthesis.

Wells et al. (1986) found a positive correlation between lint yield and canopy photosynthesis in Gossypium hirsutum. They compared a number of genotypes differing in leaf morphology: normal leaves and leaves with varying degrees of incision. Decreased canopy photosynthesis by the genotypes with incised leaves was due to poorer light interception; ca. $30 \%$ of the light penetrated to ground level in crops of genotypes with severe incisions, as opposed to ca. $5 \%$ in crops of normal cotton plants. The better performance of the genotypes with normal leaves was therefore not due to improved photosynthesis per unit area, but to their greater interception of light.

Ceulemans et al. (1985) measured the field productivity and photosynthetic characteristics of clones of Populus. A close positive correlation was found between these two parameters.

Variation in crop growth rate of a number of genotypes of a Lolium perenne population was correlated with the rate of mature leaf respiration (Wilson, 1982). In an earlier selection of Lolium genotypes, also on the basis of mature leaf respiration, no difference in photosynthetic capacity was found (Wilson, 1975). Robson (1982b) concluded that the difference in yield of two populations, descending from some fast growing and some slow growing Lolium genotypes, was entirely due to their difference in mature leaf respiration.

\section{Variation in net assimilation rate}

The higher NAR in the shade-tolerant Geum urbanum in comparison with the shade-avoiding Cirsium palustre was due to a greater photosynthetic activity per unit area (Pons, 1977). This was also found in a comparison of Plantago major genotypes: those with the highest NAR had the highest photosynthetic capacity (Dijkstra \& Lambers, 1986).

Respiration is also a major component of NAR; some $50 \%$ of the photosynthates produced daily may be lost in the respiration of the various plant parts (Lambers, 1985). The respiratory component is too often forgotten, although there are large variations between species in respiration, especially the respiration of roots (Lambers, 1979). This variation is partly explained by a difference in the contribution of the alternative path (Lambers et al., 1983), a non-phosphorylating mitochondrial electron transport pathway (Laties, 1982; Lambers, 1985). To some extent it is also explained by differences in energy requirement for growth, maintenance and ion transport (van der Werf et al., in press).

Leaves of shade-tolerant genotypes have an inherently low respiration rate, expressed per unit leaf area (Pons, 1977). This is related to their lower weight per unit leaf area.

Robson (1982b) concluded that the difference in respiration between popula- 


\section{H. LAMBERS}

tions of Lolium perenne (Wilson, 1982) could account for differences in their seedling growth, and larger differences at a later stage, after cutting (Wilson, 1982; Robson, 1982a). The higher rate of respiration is not due to a larger contribution of the non-phosphorylating, alternative path (Day et al., 1985).

Variation in net assimilation rate can be due to the respiratory component, but very few studies have concentrated on this aspect. Many investigations demonstrate that a high net assimilation rate is correlated with a high rate of photosynthesis. In comparisons of $\mathrm{C}_{3}$ and $\mathrm{C}_{4}$ species, differences in photosynthesis can be ascribed to anatomical and biochemical characteristics which are vastly different between such contrasting species (Osmond et al., 1982). In comparisons of only $\mathrm{C}_{3}$ species or only $\mathrm{C}_{4}$ species, differences in the rate of photosynthesis are likely to have a less spectacular basis.

\section{Variation in photosynthesis}

Concentration of rubisco and other nitrogenous components associated with photosynthesis

Variation in the rate of photosynthesis is often correlated with the concentration of nitrogenous compounds in the leaves (e.g. Mooney et al., 1981; Evans, 1983; Hunt et al., 1985; Hirose \& Werger, 1987a). This correlation is explained by the fact that some $75 \%$ of all $\mathrm{N}$ in the mesophyll cells of $\mathrm{C}_{3}$ plants is associated with photosynthesis (Evans, 1984). A large fraction of this $\mathrm{N}$ is part of the enzyme Rubisco (ribulose-bisphosphate carboxylase; ca. $25 \%$ of all the $\mathrm{N}$ in mesophyll cells of $\mathrm{C}_{3}$ plants; Evans, 1984). The rate of photosynthesis is therefore also closely correlated with the Rubisco activity in the leaves (Evans, 1983).

\section{Leaf anatomy}

\section{Mesophyll size}

Wilson \& Cooper (1970) compared a number of Lolium perenne genotypes, differing in the sizes of their mesophyll cells. Genotypes with small mesophyll cells had higher shoot dry matter yields, which was partly related to their higher net assimilation rate (Fig. 1) and partly to their higher seed weight. The rate of light-saturated photosynthesis was negatively correlated with mesophyll size. The leaf area aratio of the genotypes with the smaller mesophyll cells and higher yield was lower than that of the genotypes with larger cells (Fig. 1), so that the RGR of genotypes with small mesophyll cells and those with large cells was exactly the same, at least after the third leaf stage. There is, however, a strong interaction between photoperiod and both LAR and NAR, so that in certain environments the higher NAR might well be associated with a higher RGR (cf. the discussion in Wilson \& Cooper, 1970).

The positive correlation between mesophyll cell size and leaf area ratio (Fig. 1; Wilson \& Cooper, 1970) is interesting in view of the observation that the ratio of the area of the mesophyll cells and that of the leaf $\left(A_{\text {mes }} / A\right)$ generally increases with in- 

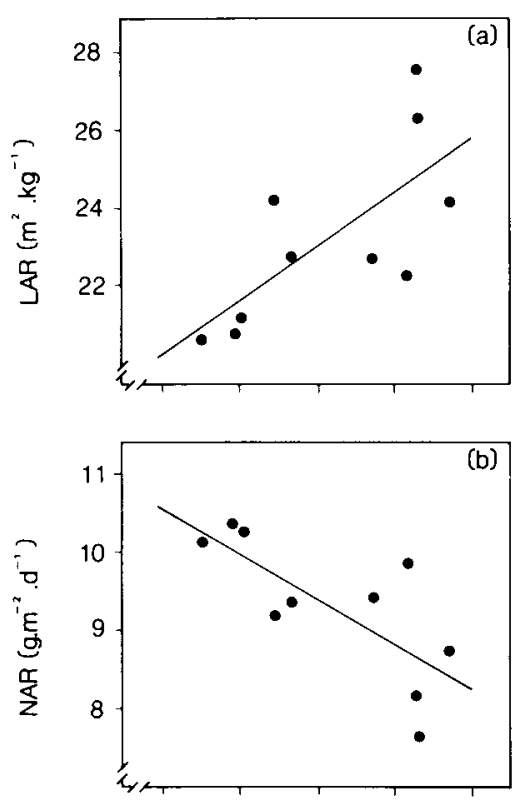

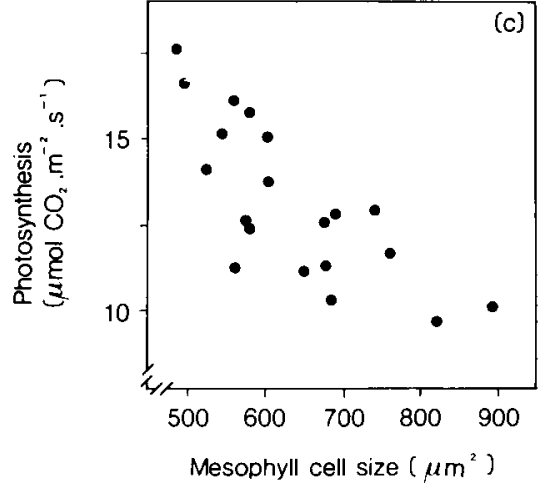

Fig. 1. The leaf area ratio, net assimilation rate and photosynthetic capacity in a number of Lolium perenne genotypes, differing in mesophyll size. Figures are based on information in Wilson \& Cooper (1970).

creasing quantum flux density during growth (Björkman, 1981). It can be calculated that this ratio was also higher in the Lolium genotypes with small mesophyll cells. Both the small mesophyll cells and the low leaf area ratio may point to adaptation to a high quantum flux density of these genotypes and vice versa.

The higher rate of light-saturated photosynthesis in genotypes with small mesophyll cells (Fig. 1) can be explained, if diffusion of $\mathrm{CO}_{2}$ from the intercellular spaces to the site of carboxylation exerts a major limitation to photosynthesis. Such a limitation must be smaller in genotypes with small mesophyll cells, as this may reduce the diffusion path length. However, the higher NAR and light-saturated photosynthesis were also positively associated with the chlorophyll concentration and the to- 
tal amount of leaf dry weight per unit leaf area. Presumably, both a greater mesophyll conductance for $\mathrm{CO}_{2}$ diffusion and a greater photosynthetic capacity contributed to the higher rate of light-saturated photosynthesis.

A major question remains: why was the higher NAR in the Lolium genotypes compensated by a lower LAR? Such a negative association is by no means unique for Lolium. In a comparison of the growth of genotypes of Dactylus glomerata (Eagles, 1967), of Cirsium palustre with Geum urbanum (Pons, 1977), and of Plantago major genotypes, a similar (partial) compensation was found. This observation might be explained on the assumption that the hydraulic conductance of the roots is a major constraint for the water flow in the plants. Any increase in photosynthetic rate due to increased stomatal conductance is bound to increase the rate of transpiration, be it not necessarily entirely proportional. An increased root mass in proportion to the leaf area, i.e. a decreased leaf area ratio, must then be the inevitable effect. There is also an additional, more straightforward, explanation for the lower LAR at a high NAR. A higher NAR, when associated with more photosynthetic enzymes and pigments per unit area, as in Lolium (Wilson \& Cooper, 1970), will lead to a reduction in SLA and thus LAR. Only when the decreased LAR can be entirely explained by increased mass per unit leaf area, the first explanation need not be invoked.

\section{Sun and shade leaves}

The higher rate of photosynthesis of sun leaves compared to shade leaves, is generally correlated with more layers of palisade parenchyma cells (e.g. Groen, 1973). The chlorophyll concentration per unit fresh weight tends to be higher for shade leaves, whereas that of protein and the activity of Rubisco is lower (Björkman, 1981). Increased chlorophyll concentrations, especially of chlorophyll b, is likely to lead to a somewhat greater efficiency of light utilization at a low quantum flux density (Björkman, 1981). However, a high chlorophyll concentration, extensive grana stacking and the large intrathylakoid space may also be a prerequisite to enable efficient use of lightflecks. Postillumination $\mathrm{CO}_{2}$ assimilation in shade leaves which efficiently use the quanta during lightflecks may increase photosynthesis by $60 \%$ (Sharkey et al., 1986).

\section{The cuticle}

The presence of a thick cuticle on xeromorphic leaves is often interpreted in terms of reduced water loss. However, the permeance coefficient of the isolated cuticle of Nerium oleander, which is ca. $12 \mu \mathrm{m}$ thick, is not significantly different from that of isolated cuticles of, for example, Hedera helix, Ficus elastica, or Clivia miniata, whose cuticle is two to three times as thin (Becker et al., 1986). There is no evidence to support the hypothesis that thick cuticles reduce passive water flow from the plant. Structure and chemical composition of the cuticular membranes are also important and a thin cuticle may be just as effective as a thick one.

Presumably a major function of thick cuticle is to increase the reflection and thus decrease the leaf's temperature. Mulroy (1979) compared the spectral properties of heavily glaucous and non-glaucous leaves of the succulent Dudleya brittonii. Glau- 
cescence, due to a powdery wax coating on the leaf surface, is responsible for very high reflectance in the UV, visible and near-infrared region. Glaucous leaves are often found on plants in dry climates, where the level of radiation is high. Although the waxes will reduce the number of photons available for photosynthesis, their presence is likely to lead to a temperature closer to the optimum for photosynthesis. Additionally, they will reduce water loss, due to the lowered leaf temperature.

\section{Leaf morphology}

\section{Leaf pubescence}

The significance of leaf pubescence has been well studied for a number of contrasting situations. Leaf pubescence of Encelia farinosa, a desert species with a white appearance connected with its short white hairs, reduces the absorption of solar radiation, due to an increased albedo (Ehleringer et al., 1976). This reduces the rate of photosynthesis, but will reduce transpiration proportionally even more, due to the lower leaf temperature. The lower leaf temperature may also allow photosynthesis, as well as other leaf processes, to operate closer to their optimum temperature.

The significance of pubescence in African and Andean giant rosettes, which occur in higher tropical mountains, is to decrease the sensible heat loss, and thus to increase leaf temperature (Meinzer et al., 1985). Naturally the hairs on these leaves also reduce the absorption of solar radiation and so leaf temperature, but this is more than compensated by their effect on the boundary layer. Hairs of such plants, such as of Espeletia schultzii, are not white and considerably longer (1.1. to $2.6 \mathrm{~mm}$, depending on altitude) than those on plants from hot and arid habitats. Meinzer \& Goldstein (1985) measured leaf temperatures of Espeletia timotensis, also from the Andes at altitudes up to $4500 \mathrm{~m}$, and found that the temperature of the pubescent leaves was higher than that of leaves of which $50 \%$ of the hairs had been removed by 'shaving', as soon as the solar radiation was above $300 \mathrm{~W} \mathrm{~m}^{-2}$. The largest difference measured was ca. $4{ }^{\circ} \mathrm{C}$. They further simulated leaf temperature, under a range of environmental conditions, with good agreement between predicted and measured leaf temperatures. Their model predicts that the temperature of the pubescent leaves can be as much as $10^{\circ} \mathrm{C}$ above ambient under the prevailing growth conditions. The difference between leaf temperature and air temperature are largests at lower air temperatures and also at higher levels of incident solar radiation. At low levels of solar radiation, the model predicted the leaf temperature to be lower than ambient. This prediction was confirmed by measurements in the field, showing that glabrous leaves had a higher temperature at night and in the early morning than the pubescent ones. Lower temperatures of pubescent leaves at night are thought to be due to the effect of hairs on long-wave emission to the night sky.

Even on cooler days, with maximum temperatures below $8{ }^{\circ} \mathrm{C}$, leaf temperatures of $15-20^{\circ} \mathrm{C}$ were commonly observed. At least part of this rise must be due to the long hairs on the leaves. Such a rise in leaf temperature is likely to increase the rate of net $\mathrm{CO}_{2}$ assimilation as well as other physiological processes, considering that maximum air temperatures are usually below $10^{\circ} \mathrm{C}$. 


\section{H. LAMBERS}

\section{Leaf size}

Like pubescence, the size of the leaves is also important for the boundary layer conductance to heat and gas exchange. The boundary layer conductance of a flat leaf is inversely proportional to the square root of the leaf dimension, measured in the direction of the wind, and proportional to the square root of the wind speed (Nobel, 1981). Thus, small leaves have a greater boundary layer conductance, and long narrow leaves tend to have a greater boundary layer conductance when hanging, than when in a horizontal plane. However, large effects of the boundary layer are to be expected only when the conductance of the boundary layer is of the same order of magnitude as the stomatal conductance. The conductance of the boundary layer of leaves generally ranges from 10 to $100 \mathrm{~mm} \mathrm{~s}^{-1}$ for a wind speed of $1 \mathrm{~m} \mathrm{~s}^{-1}$, while the total water vapour conductance for open stomata is 1 to $10 \mathrm{~mm} \mathrm{~s}^{-1}$ (Nobel, 1981).

Leaf width tends to decrease with height (e.g. in rain-forests), with decreasing availability of nutrients in the root environment, and with increasing moisture stress (Givnish, 1984). The functional significance of this becomes obvious when considering the exchange of heat, water vapour and $\mathrm{CO}_{2}$, as dependent on stomatal and boundary layer conductance (cf. Campbell, 1981).

At greater height in a rain-forest, the quantum flux density and vapour pressure deficits are higher. Larger leaves, with their smaller boundary layer conductance, would loose less heat by convection than the smaller ones actually found at greater height: larger leaves have a higher temperature at a high quantum flux density. Larger leaves high up in the canopy would therefore have a higher transpiration rate, whereas photosynthesis is unlikely to be positively affected. The water use efficiency of large leaves at high quantum flux density is therefore lower than that of small leaves. Lower in the canopy, where the radiation level is lower, there is no need for small leaves: larger leaves have a lower temperature at a very low quantum flux density. A decreased boundary layer conductance of the larger leaves might here even reduce the transpiration rate.

The variation in leaf size along a gradient of nutrient supply can be explained in a similar manner. At a low supply of nitrogen, the nitrogen concentration in the leaf will be low. Stomatal conductance will be reduced proportionally (cf. Farquhar \& Sharkey, 1982) and leaf cooling via transpiration (latent heat loss) will be small. The greater boundary layer conductance of the smaller leaves will allow increased heat loss due to convection, thus preventing the leaf temperature to rise too much. Consequently, the transpiration of smaller leaves with a low stomatal conductance is less than that of larger leaves with similarly low conductance. At fertile sites, where leaves have higher nitrogen concentrations and greater stomatal conductance, heat loss is largely by transpiration and there is no need for structures increasing heat loss by convection. Here, larger leaves are favoured, as this will reduce transpiration, due to their smaller boundary layer conductance (cf. Givnish, 1984).

The variation in leaf size along a gradient of water availability can be explained along similar lines. However, the above concepts need further testing: careful collection of experimental data need to be combined with studies in which the exchange of heat, water vapour and $\mathrm{CO}_{2}$ are simulated as a function of leaf size and 
stomatal conductance (cf. Campbell, 1981). The genetic variation for leaf size, in combination with that for rate of flag leaf photosynthesis (Apel et al., 1973), might be exploited for selection of varieties for specific environments.

\section{Leaf dissection}

Just like small leaves, dissected leaves have a higher boundary layer conductance. Leaves of Malva moschata, for example, which are found lower in the canopy are often entire, whilst the ones nearer the top of the canopy show a progressive increase in leaf dissection (Fitter \& Hay, 1981). Genotypic variation in the degree of incision has also been found, for example between cultivars of Gossypium hirsutum (Wells et al., 1986). The significance of the gradient in degree of dissection as observed for Malva, is the same as that described for a gradient in leaf size, discussed above. Following the same reasoning, one might expect the cotton genotypes with a low degree of incision to perform better with ample water supply (as found by the authors), whilst the ones with incised leaves might perform better when water becomes a major limiting factor for productivity.

\section{Stomatal conductance}

Stomatal conductance for diffusion of $\mathrm{CO}_{2}$ tends to be regulated in such a manner that Rubisco and electron transport are co-limiting (Farquhar \& Sharkey, 1982). A greater conductance would only cause a slightly higher rate of photosynthesis, but transpiration would increase proportionally more. Johnson et al. (1987) compared the gas exchange characteristics of two Triticum species. T. kotschyi, a desert annual, had a higher conductance, internal $\mathrm{CO}_{2}$ concentration and rate of $\mathrm{CO}_{2}$ assimilation than $T$. aestivum. Consequently, its water use efficiency was lower. However, since the curves describing photosynthesis as a function of the internal $\mathrm{CO}_{2}$ concentration were very similar for the two species, $T$. kotschyi must have a higher rate of photosynthesis per unit of nitrogen in the leaves. Similar differences in gas exchange properties are likely to occur between cultivars of Triticum aestivum: they are considered of significance in adaptation to environments where water may be limiting (Farquhar \& Richards, 1984).

\section{Heliotropism}

Leaves of some plants have the capacity to orient their leaves so that they are perpendicular to the incident radiation (diaheliotropic leaves). Under conditions of water stress they may orient their leaves parallel to the incident radiation (paraheliotropic leaves). Diaheliotropism leads to significant increases in the daily assimilation of $\mathrm{CO}_{2}$, whereas the significance of paraheliotropism is to reduce water loss (Ehleringer, 1985).

\section{Optimization of leaf size and nitrogen distribution over the canopy}

There is an increasing amount of evidence that size and shape of leaves vary with prevailing environmental conditions in a manner which increases the water use efficiency and/or rate of $\mathrm{CO}_{2}$ assimilation of the inividual leaves. Whether leaf size and 


\section{H. LAMBERS}

shape are optimal, given the prevailing environmental conditions, cannot yet be stated with any degree of certainty. Simulation models, in combination with the careful collection of experimental data, is required to further develop this area of research. A similar approach has been proven to be very useful with regard to the distribution of nitrogen over the various layers in a canopy.

Hirose \& Werger (1987a) measured photosynthesis of Solidago altissima leaves as a function of their nitrogen concentration and at a range of quantum flux densities. They also measured the distribution of light in the canopy and the concentration of nitrogen in the leaves from the top to the bottom of the canopy. The authors conclude that the distribution of nitrogen over the different leaves is such that an optimum investment pattern is approached. Investment of nitrogen in such a manner that the concentration is the same in the top and bottom leaves would have led to a $20 \%$ lower rate of photosynthesis. Photosynthesis of plants having the actual distribution of nitrogen differed from that having an optimum distribution by only $4.7 \%$ (Hirose \& Werger, 1987b).

\section{Are there possibilities for improvement of crop performance by changing the plant's photosynthetic characteristics?}

This paper includes examples of correlations between growth rate or productivity and NAR. In a number of studies a high NAR was shown to be due to a greater photosynthetic capacity. It appears therefore that there is scope for improving crop productivity by increasing the plant's photosynthetic capacity. Questions to be answered remain: (1) Is it crop photosynthesis, or photosynthesis of individual leaves that needs to be selected for? (2) Can we improve crop photosynthesis by optimizing allocation of resources and/or leaf morphological characteristics?

Comparing the photosynthetic performance of either $\mathrm{C}_{3}$ species or $\mathrm{C}_{4}$ species has led to the conclusion that the basic biochemistry is identical. However, due to variation in stomatal conductance, chlorophyll concentration, Rubisco activity, leaf size, the presence of waxes or hairs, etc., photosynthetic performance of leaves may differ. There are also costs associated with an increased photosynthetic capacity: increased stomatal conductance reduces the water use efficiency; increased activity of Rubisco is only beneficial for leaves exposed to a high quantum flux density, or when plants are supplied with abundant nitrogen; hairs and waxes require biosynthetic costs. Within an individual plant, photosynthetic performance can be increased by variation in leaf nitrogen concentration, leaf dissection and leaf size.

Increased photosynthesis per unit leaf area requires greater investment of nitrogen per unit leaf area. Such an investment may be at the expense of the efficiency of nitrogen utilization, so that the ultimate (agronomic) gain is possibly marginal or non-existent. Selection for optimum distribution of nitrogen over the canopy (cf. Hirose \& Werger, 1987b), if genetic variation exists, will increase canopy photosynthesis. Selection for plants with anatomical or morphological structures (leaf size, hairs and cuticular wax layers) which reduce the heat load may lead to better performance in some environments.

Attempts to select for genotypes with higher canopy photosynthesis may be more 
successful if the 'optimization approach' (cost/benefit analysis; Bloom et al., 1985), recently gaining popularity in ecological research, is taken into account. Such an approach needs to combine several morphological, anatomical, physiological and biochemical aspects. Simulation models, though they can never replace making the careful measurements, may be of some help to deal with the order of complexity needed in the suggested approach.

\section{Acknowledgements}

I would like to thank Adrie van der Werf for his constructive and helpful comments on this manuscript.

\section{References}

Apel, P., C. O. Lehmann \& A. Friedrich, 1973. Beziehungen zwischen Fahnenblattfäche, Photosynthesenrate und Einzelährenertrag bei Sommerweizen. Kulturpflanzen 21: 89-95.

Becker, M., G. Kerstiens \& J. Schönherr, 1986. Water permeability of plant cuticles: permeance, diffusion and partition coefficients. Trees 1: 54-60.

Björkman, O., 1981. Responses to different quantum flux densities. In: O. L. Lange, P. S. Nobel, C. B. Osmond \& H. Ziegler (Eds.), Encyclopedia of plant physiology, N.S., Vol. 12A, p. 57-107. SpringerVerlag, Berlin.

Bloom, A. J., F. S. Chapin, III \& H. A. Mooney, 1985. Resource limitation in plants - an economic analogy. Annual Review of Ecology and Systematics 16: 363-392.

Campbell, G. S., 1981. Responses to different quantum flux densities. In: O. L. Lange, P. S. Nobel, C. B. Osmond \& H. Ziegler (Eds.), Encyclopedia of plant physiology, N.S., Vol. 12A, p. 11-40.

Ceulemans, R., I. Impens \& V. Steenackers, 1984. Poplar: an ecophysiological approach. Nederlands Bosbouwtijdschrift 57: 48-59.

Corré, W. J., 1983. Growth and morphogenesis of sun and shade plants. III. The combined effects of light intensity and nutrient supply. Acta Botanica Neerlandica 32: 277-294.

Dijkstra, P. \& H. Lambers, 1986. Photosynthesis and respiration of two inbred lines of Plantago major L. differing in relative growth rate. In: R. Marcell, H. Clijsters \& M. van Poucke (Eds.), Biological control of photosynthesis, p. 251-255. Martinus Nijhoff Publishers, Dordrecht.

Eagles, C. F., 1967. The effect of temperature on vegetative growth in climatic races of Dactylis glomerata in controlled environments. Annals of Botany 31: 31-39.

Ehleringer, J., 1985. Annuals and perennials of warm deserts. In: B. F. Chabot \& H. A. Mooney (Eds.), Physiological ecology of North American plant communities, p. 162-180. Chapman and Hall, New York.

Ehleringer, J., O. Björkman \& H. A. Mooney, 1976. Leaf pubescence: Effects on absorptance and photosynthesis in a desert shrub. Science 192; 376-377.

Evans, J. R., 1983. Nitrogen and photosynthesis in the flag leaf of wheat (Triticum aestivum L.). Plant Physiology 72: 297-302.

Evans, J. R., 1984. Photosynthesis and nitrogen partitioning in leaves of Triticum aestivum and related species. Ph. D. Thesis, Australian National University, Canberra, 144 pp.

Farquhar, G. D. \& R. A. Richards, 1984. Isotopic composition of plant carbon correlates with water-use efficiency of wheat genotypes. Australian Journal of Plant Physiology 11: 539-552.

Farquhar, G. D. \& T. D. Sharkey, 1982. Stomata and photosynthesis. Annual Review of Plant Physiology 33: 317-345.

Gifford, R. M., J. H. Thorne, W. D. Hitz \& R. T. Giaquinta, 1984. Crop productivity and photoassimilate partitioning. Science 225: 801-808.

Givnish, T. J., 1984. Leaf and canopy adaptations in tropical forests. In: E. Medina, H. A. Mooney \& C. Vázquez-Yánes (Eds.), Physiological ecology of plants of the wet tropics, p. 51-84. Dr W. Junk Publishers, The Hague. 


\section{H. LAMBERS}

Grime, J. P. \& R. Hunt, 1975. Relative growth-rate: Its range and adaptive significance in a local flora. Journal of Ecology 63: 393-422.

Groen, J., 1973. Photosynthesis of Calendula officinalis L. and Impatiens parviflora DC., as influenced by light intensity during growth and age of leaves and plants. Communications Agricultural University, Wageningen, Netherlands $73-8,128 \mathrm{pp}$

Higgs, D. E. B. \& D. D. James, 1969. Comparative studies on the biology of upland grasses. I. rate of dry matter production and its control in four grass species. Journal of Ecology 57: 553-564.

Hirose, T. \& M. J. A. Werger, 1987a. Nitrogen use efficiency in instantaneous and daily photosynthesis of leaves in the canopy of a Solidago altissima stand. Physiologia Plantarum 70: 215-222.

Hirose, T. \& M. J. A. Werger, 1987b. Maximizing daily canopy photosynthesis with respect to leaf nitrogen allocation pattern in the canopy. Oecologia 72: 520-526.

Hunt, E. R., J. A. Weber \& D. M. Gates, 1985. Effects of nitrate application on Amaranthus powelii Wats. II. Optimal allocation of leaf nitrogen for photosynthesis and stomatal conductance. Plant Physiology 79: 619-624.

Hunt, R., 1982. Plant growth curves. The functional approach to growth analysis. Edward Arnold, London, $248 \mathrm{pp}$.

Jarvis, P. G. \& M. S. Jarvis, 1964. Growth rates of woody plants. Physiologia Plantarum 17: 654-666.

Johnson, R. C., D. W. Mornhinweg, D. M. Ferris \& J. J. Heitholt, 1987. Leaf photosynthesis and conductance of selected Triticum species at different water potentials. Plant Physiology 83: 1014-1017.

Kuiper, D., 1983. Genetic differentiation in Plantago major: Growth and root respiration and their role in phenotypic adaptation. Physiologia Plantarum 57: 222-230.

Lambers, H., 1979. Efficiency of root respiration in relation to growth rate, morphology and soil composition. Physiologia Plantarum 46: 194-202.

Lambers, H., 1985. Respiration in intact plants and tissues: Its regulation and dependance on environmental factors, metabolism and invaded organisms. In: R. Douce \& D. A. Day (Eds.), Encyclopedia of plant physiology, N.S. Vol. 0, p. 418-473. Springer-Verlag, Berlin.

Lambers, H. \& P. Dijkstra, 1987. A physiological analysis of genetic variation in relative growth rate: Can growth rate confer ecological advantage? In: J. van Andel, J. P. Bakker \& R. W. Snaydon (Eds.), Disturbance in grasslands. Causes, effects and processes, p. 239-253. Dr W. Junk Publishers, Dordrecht.

Lambers, H. \& F. Posthumus, 1980. The effects of light intensity and relative humidity on growth rate and root respiration of Plantago lanceolata and Zea mays. Journal of Experimental Botany 31: 16211630 .

Lambers, H., D. A. Day \& J. Azcón-Bieto, 1983. Cyanide-resistant respiration on roots and leaves. Measurements with intact tissues and isolated mitochondria. Physiologia Plantarum 58: 148-154.

Laties, G. G., 1982. The cyanide-resistant, alternative path in higher plant respiration. Annual Review of Plant Physiology 33: 519-555.

Meinzer, F. \& G. Goldstein, 1985. Some consequences of leaf pubescence in the Andean giant rosette plant Espeletia timotensis. Ecology 66: 512-520.

Meinzer, F. C., G. H. Goldstein \& P. W. Rundel, 1985. Morphological changes along an altitude gradient and their consequences for an Andean giant rosette plant. Oecologia 65: 278-283.

Mooney, H. A., C. Field, S. L. Gulmon \& F. A. Bazzaz, 1981. Photosynthetic capacity in relation to leaf position in desert versus old-field annuals. Oecologia 50: 109-112.

Mulroy, T. W., 1979. Spectral properties of heavily glaucous and non-glaucous leaves of a succulent rosette-plant. Oecologia 38: 349-357.

Nobel, P., 1981. Wind as an ecological factor. In: O. L. Lange, P. S. Nobel, C. B. Osmond \& H. Ziegler (Eds.), Encyclopedia of plant physiology, N.S. Vol. 12A, p. 475-500. Springer-Verlag, Berlin.

Osmond, C. B., K. Winter \& H. Ziegler, 1982. Functional significance of different pathways of $\mathrm{CO}_{2}$ fixation in photosynthesis. In: O. L. Lange, P. S. Nobel, C. B. Osmond \& H. Ziegler (Eds.), Encyclopedia of plant physiology, N.S. Vol. 12B, p. 479-547. Springer-Verlag, Berlin.

Pons, T. L., 1977. An ecophysiological study in the field layer of ash coppice. II. Experiments with Geum urbanum and Cirsium palustre in different light intensities. Acta Botanica Neerl. 26: 29-42.

Robson, M. J., 1982a. The growth and carbon economy of selection lines of Lolium perenne with 'fast' and 'slow' rates of mature leaf respiration. 1. Grown as simulated swards during a regrowth period. Annals of Botany 49: 321-329. 


\section{VARIATION IN PHOTOSYNTHETIC RATE, GROWTH RATE AND YIELD}

Robson, M. J., 1982b. The growth and carbon economy of selection lines of Lolium perenne cv. S23 with 'fast' and 'slow' rates of dark respiration. 2. Grown as young plants from seeds. Annals of Botany 49: 331-339.

Sharkey, T. D., J. R. Seemann \& R. W. Pearcy, 1986. Contribution of metabolites to postillumination $\mathrm{CO}_{2}$ assimilation in response to lightflecks. Plant Physiology 82: 1063-1068.

Van der Werf, A., A. Kooijman, R. Welschen \& H. Lambers, 1988. Respiratory costs for the maintenance of biomass, for growth and for ion uptake in roots of Carex diandra and Carex acutiformis. Physiologia Plantarum 00: 000-000.

Warren Wilson, J., 1981. Analysis of growth, photosynthesis and light interception for single plants and sands. Annals of Botany 48: 507-512.

Wells, R., W. R. Meredith, Jr. \& J. R. Williford, 1986. Canopy photosynthesis and its relationship to plant productivity in near-isogenic cotton lines differing in leaf morphology. Plant Physiology 82: 635640.

Wilson D., 1975. Variation in leaf respiration in relation to growth and photosynthesis of Lolium. Annals of Applied Biology 80: 323-338.

Wilson, D., 1982. Response to selection for dark respiration rate of mature leaves in Lolium perenne and its effects on growth of young plants and simulated swards. Annals of Botany 49: 303-312.

Wilson, D. \& J. P. Cooper, 1970. Effect of selection for mesophyll cell size on growth and assimilation in Lolium perenne L. New Phytologist 69: 233-245. 